'Instituto de Terapéutica

Experimental y Clínica, Centro Universitario de Ciencias de

la Salud, Departamento de

Fisiología, Universidad de Guadalajara. Guadalajara, Jalisco, México. aMSc. ${ }^{\mathrm{b} P h D C}$.

CPhD.

dLicenciada en Nutrición.

Source of financial support None declared.

Recibido el 21 de mayo de 2019, aceptado el 8 de mayo de 2020 .

Corresponding author Dr. En C. Lizet Yadira Rosales-Rivera. Sierra Mojada 950, Colonia Independencia, CP. 44340, Guadalajara, Jalisco, México. lizet.rosales@gmail.com

\section{Ambulatory arterial stiffness index in diabetic patients}

\author{
CRISTAL DÍAZ-CRUZ ${ }^{1, a, b}$, ANAYELI DE JESÚS PATIÑO-LAGUNA ${ }^{1, a, b, d}$, \\ LIZET Y. ROSALES-RIVERA ${ }^{1 \mathrm{a}, \mathrm{c}}$, IMELDA LOREDO-PADRÓN $^{1, \mathrm{~b}}$, \\ ESPERANZA MARTÍNEZ-ABUNDIS ${ }^{1, \mathrm{a}, \mathrm{c}}$, MANUEL GONZÁLEZ-ORTIZ ${ }^{1, \mathrm{a}, \mathrm{c}}$
}

\section{ABSTRACT}

Background: The ambulatory arterial stiffness index (AASI), derived from $24 \mathrm{~h}$ ambulatory blood pressure monitoring (ABPM) can be a good indicator of arterial stiffness. Aim: To assess the correlation between AASI and brachial-ankle pulse wave velocity (baPWV), ankle-brachial index ( $A B I)$ and cardio-ankle vascular index (CAVI) in patients with type 2 diabetes mellitus without hypertension. Material and Methods: Cross sectional study in 28 diabetic patients aged $49 \pm 7$ years ( $40 \%$ women). AASI was calculated as 1 minus the regression slope of diastolic on systolic blood pressure, using ABPM data. ABPM was measured in the arm using an oscillometric device. $A B I$ was calculated as the ratio between ankle and brachial systolic blood pressure. CAVI was derived from pulse wave velocity using the Vasera VS-1000 device. Correlations were calculated using a bivariate Spearman correlation. Results: The mean values for AASI, $A B I, b a P W V$ and CAVI were $0.39 \pm 0.14,1.14 \pm 0.09,15.15 \pm 2.71 \mathrm{~m} / \mathrm{s}$ and $7.60 \pm 1.90$, respectively. There was a significant negative correlation between AASI and ABI $(r=-0.491, p<0.01)$. Conclusions: In these diabetic patients, there was an association between AASI, an arterial stiffness marker and ABI, an indicator for the presence of atherosclerosis.

(Rev Med Chile 2020; 148: 496-499)

Key words: Ankle Brachial Index; Atherosclerosis; Blood Pressure Monitoring, Ambulatory: Diabetes Mellitus, Type 2; Vascular stiffness.

\section{Índice de rigidez arterial ambulatorio en pacientes diabéticos}

\begin{abstract}
Antecedentes: El indice de rigidez arterial ambulatorio (AASI), derivado del monitoreo ambulatorio de presión arterial de $24 \mathrm{~h}$ (MAPA), puede ser un buen indicador de rigidez arterial. Objetivo: Evaluar la correlación entre el AASI y la velocidad de onda de pulso braquial (VOP), el indice tobillo-brazo (ITB) y el indice vascular cardio-tobillo (CAVI) en pacientes con diabetes mellitus tipo 2 sin hipertensión arterial. Material y Métodos: Estudio transversal en 28 pacientes con diabetes de $49 \pm 7$ años (40\% mujeres). El AASI se calculó como 1 menos la pendiente de regresión de la presión arterial diastólica sobre la sistólica, usando datos del MAPA de $24 \mathrm{~h}$, el cual se midió en el brazo, usando un dispositivo oscilométrico. El ITB se calculó como la razón entre la presión arterial sistólica del tobillo sobre la del brazo. El CAVI se derivó de la velocidad de onda de pulso medida con el dispositivo Vasera VS-1000. Para el análisis estadístico se utilizó el coeficiente de correlación bivariada de Spearman. Resultados: Los valores de
\end{abstract}


AASI, VOP, ITB y CAVI fueron $0.39 \pm 0.14,1.14 \pm 0.09,15.15 \pm 2.71 \mathrm{~m} / \mathrm{s} y$ $7.60 \pm 1.90$, respectivamente. Hubo una correlación negativa significativa entre AASI e ITB $(r=-0.491, p<0.01)$. Conclusiones: Hay una asociación entre AASI, un marcador de rigidez arterial e ITB, un indicador de aterosclerosis, en estos pacientes con diabetes mellitus tipo 2.

Palabras clave: Arterioesclerosis; Diabetes mellitus tipo 2; Monitoreo ambulatorio de la presión arterial; Rigidez vascular.

\section{A} therosclerosis and endothelial dysfunction have been associated with type 2 diabetes mellitus $(\mathrm{T} 2 \mathrm{DM})^{1}$. Brachial index of the ankle (ABI) could be used to assess atherosclerosis; on the other hand, to evaluate the endothelial dysfunction, through arterial stiffness, one could measure the brachial pulse wave velocity (baPWV) and determine the cardio-ankle vascular index $(\mathrm{CAVI})^{2,3}$. The ambulatory arterial stiffness index (AASI) has been proposed as a novel measure to determine endothelial dysfunction ${ }^{4}$; however, there is not enough evidence to correlate the AASI with the previously mentioned evaluations. The aim of the study was to determine the correlation of $24 \mathrm{~h}$ ASSI with ABI, baPWV, and CAVI in T2DM patients without hypertension.

\section{Methods}

We carried out a cross-sectional study in 28 patients of both sexes (40-60 year-old), with recently diagnosed T2DM according to the criteria of the American Diabetes Association, without treatment $^{4}$. Patients with fasting plasma glucose (FPG) $<13.8 \mathrm{mmol} / \mathrm{l}$, glycated hemoglobin A1c (A1C) $<10 \%$ and a body mass index (BMI) between 25 and $34.9 \mathrm{~kg} / \mathrm{m}^{2}$ were included. All subjects were sedentary, non-smokers, without hypertension, renal, cardiac, thyroid or hepatic disease; pregnant or lactating women were excluded.

The enrolled subjects were evaluated after an overnight fasting from 10 to $12 \mathrm{~h}$.

Body weight (BW) and height were measured with a digital scale (Tanita TBF-215A, TANITA Corporation, Tokyo, Japan). The BMI was calculated with the Quetelet index. Blood pressure (BP) was determined with an oscillometric blood pressure monitor (HEM-907-E, Omron, Kyoto, Japan).

The FPG, triglycerides (TG), total cholesterol (TC), and high-density lipoprotein cholesterol
(HDL-C) levels were determined by colorimetric methods with a biochemical analyzer (Erba XL $100^{\mathrm{TM}}$, Mannheim, Germany). The percentage of A1C was measured using a high-performance liquid chromatography (HPLC) (Bio-Rad Laboratories, Hercules, CA, USA). Low-density lipoprotein cholesterol (LDL-C) levels were calculated with the Friedewald equation and the very low-density lipoprotein (VLDL) with the proportion of TG $(\mathrm{mmol} / \mathrm{L}) / 2.2$.

The ambulatory BP monitoring (ABPM) was recorded for $24 \mathrm{~h}$ using the Microlife WatchBP O3 (Microlife AG, Widnau, Switzerland). BP measurements were scheduled every 15 minutes during the day ( 8 a.m. to 11 p.m.) and every 30 minutes during the night (11 p.m. to 8 a.m.).

AASI was defined as one minus the regression slope of diastolic blood pressure (DBP) on systolic blood pressure (SBP) derived from the ABPM of $24 \mathrm{~h}^{5,6}$.

$\mathrm{ABI}$ and baPWV were measured with the OMRON VP-1000 plus device (Kyoto, Japan) and the shape of the pulse wave was measured with an oscillometric pressure sensor. ABI was calculated, for both legs, as the ratio between each ankle SBP divided by the highest brachial SBP.

CAVI was determined with the Vasera VS-1000 device (Fukuda Denshi, Tokyo, Japan).

Data was analyzed with the software IBM SPSS Statistics V21.0 software (SPSS, Inc., Chicago, IL, USA). Continuous variables are presented as means \pm the standard deviation and categorical variables as frequencies and percentages.

The Spearman correlation test was used to evaluate the correlation between ASSI with ABI, baPWV, and CAVI. A p $<0.05$ was considered statistically significant.

The study was consistent with the Declaration of Helsinki and the Institutional Ethics Committee approved the protocol. The informed consent was obtained. 


\section{Results}

Out of a total of 28 patients, $40 \%$ were women. The mean age was $49 \pm 7$ years, with a BMI of $30.5 \pm 3.8 \mathrm{~kg} / \mathrm{m}^{2}, \mathrm{FPG}$ of $8.65 \pm 1.8 \mathrm{mmol} / \mathrm{l}, \mathrm{AlC}$ of $8.1 \pm 0.94 \%$, TG of $1.98 \pm 1.13 \mathrm{mmol} / \mathrm{l}$, TC of $5.17 \pm 0.73 \mathrm{mmol} / \mathrm{l}, \mathrm{HDL}-\mathrm{C}$ of $0.98 \pm 0.24 \mathrm{mmol} / \mathrm{l}$, LDL-C of $3.28 \pm 0.77 \mathrm{mmol} / \mathrm{l}$, VLDL of $0.91 \pm 0.52$ $\mathrm{mmol} / \mathrm{l}, \mathrm{SBP} 122 \pm 9 \mathrm{mmHg}$, DBP $76 \pm 5 \mathrm{mmHg}$. Of the ABPM of $24 \mathrm{~h}$ : SBP was $119 \pm 11 \mathrm{mmHg}$, DBP was $74 \pm 6 \mathrm{mmHg}$ and ASSI was $0.39 \pm 0.14$. The average for ABI was $1.14 \pm 0.09$, baPWV $15.20 \pm 2.70 \mathrm{~m} / \mathrm{s}$ and CAVI $7.60 \pm 1.90$.

The coefficients of correlation between ASSI and $\mathrm{ABI}$, as well as with baPWV and CAVI are shown in Table 1.

\section{Discussion}

The results show a negative correlation between AASI and ABI in patients with T2DM without hypertension, this has already been reported in patients with hypertension without treatment ${ }^{7}$; however, this correlation disappeared in patients with longer duration of hypertension ${ }^{8}$.

In elderly patients with T2DM and hypertension, AASI has been associated with the progression of albuminuria?.

ABI is an evaluation used to confirm the diagnosis and severity of arterial disease in the lower limbs. Low values of ABI are associated with rates of concomitant coronary, cerebrovascular diseases, and with cardiovascular risk factors, so it is an indicator of generalized atherosclerosis ${ }^{10}$, even in the general population ${ }^{11-13}$. AASI has been proposed to predict fatal and non-fatal cardiovascular complications. Furthermore, AASI has been correlated with several measures of arterial stiffness for instance, aortic pulse rate, central and peripheral pressures, and the rate of systolic augmentation, but it has not been associated with atherosclerosis ${ }^{6}$. An advantage of AASI is that it can be evaluated without the need of other measurements that require time, numerous equipment, and evaluation techniques.

There is great controversy about the usefulness of AASI as a marker of arterial stiffness. Some studies have confirmed its correlation with other markers, while in others it has not been possible to prove it. Apparently the correlation depends on
Table 1. The coefficients of correlation between ASSI and ABI, baPWV and CAVI

\begin{tabular}{|lcccc|}
\hline & $\begin{array}{c}\text { ASSI } \\
\mathbf{2 4 - h}\end{array}$ & ABI & $\begin{array}{c}\text { baPWV, } \\
\mathbf{c m} / \mathbf{s}\end{array}$ & CAVI \\
\hline ASSI 24-h & 1.000 & $-0.491 *$ & -0.016 & 0.033 \\
\hline ABI & $-0.491 *$ & 1.000 & -0.064 & 0.164 \\
\hline baPWV, cm/s & -0.016 & -0.064 & 1.000 & 0.075 \\
\hline CAVI & 0.033 & 0.164 & 0.075 & 1.000 \\
\hline
\end{tabular}

ASSI: ambulatory arterial stiffness index; $\mathrm{ABI}$ : ankle-brachial index; baPWV: pulse wave velocity; CAVI: cadio-ankle vascular index. *Spearman correlation $p=0.01$ (bilateral).

age, sex, body composition, pathology, duration and whether the patient receives treatment or not. With the current evidence, it is not yet possible to rule out the usefulness of AASI as a marker of arterial function and cardiovascular outcomes ${ }^{5}$.

A limitation was the size of the sample since it did not allow adjustments, however, statistics show that the strong correlation between AASI and $\mathrm{ABI}$ is higher compared to other studies ${ }^{7,8}$. To our knowledge, this is the first study that evaluates the effectiveness of AASI in patients with T2DM without hypertension. There is still a need for more evaluations to use AASI as a surrogate marker of arterial stiffness; but it is possible to use it, along with other validated markers, for the evaluation of cardiovascular risk in patients with T2DM without hypertension.

\section{Conclusion}

An elevated AASI correlates with a low ABI in T2DM patients without hypertension.

Acknowledgments: The authors thank L. Michele Brennan-Bourdon $\mathrm{PhD}$, executive editors, Scientific Communications and Brennan Language Editing Services, for the English editorial assistance.

\section{References}

1. Sorokin A, Kotani K, Bushueva O, Taniguchi N, Lazarenko V. The Cardio-Ankle Vascular Index and Ankle-Brachial Index in Young Russians. J Atheroscler Thromb 2015; 22 (2): 211-8. 
2. Husmann M, Jacomella V, Thalhammer C, Amann-Vesti BR. Markers of arterial stiffness in peripheral arterial disease. Vasa 2015; 44 (5): 341-8.

3. Ecobici M, Stoicescu C. Arterial Stiffness and Hypertension - Which Comes First? Maedica (Buchar) 2017; 12 (3): 184-90.

4. American Diabetes Association. Classification and diagnosis of diabetes. Diabetes Care 2018; 41 (Suppl. 1): S13-27.

5. Kollias A, Stergiou GS, Dolan E, O’Brien E. Ambulatory arterial stiffness index: A systematic review and meta-analysis. Atherosclerosis 2012; 224 (2): 291-301.

6. Saner C, Simonetti GD, Wühl E, Mullis PE, Janner M. Increased ambulatory arterial stiffness index in obese children. Atherosclerosis 2015; 238 (2): 185-9.

7. García-García A, Gómez-Marcos MA, Recio-Rodríguez JI, González-Elena LJ, Parra-Sanchez J, Fe Muñoz-Moreno M, et al. Relationship between ambulatory arterial stiffness index and subclinical target organ damage in hypertensive patients. Hypertens Res 2011; 34 (2): 1806.

8. Gómez-Marcos MÁ, Recio-Rodríguez JI, Patiño-Alonso MC, Gómez-Sánchez L, Agudo-Conde C, Gómez-Sánchez $\mathrm{M}$, et al. Ambulatory arterial stiffness indices and target organ damage in hypertension. BMC Cardiovasc Disord 2012; 12: 1.

9. Palmas W, Pickering T, Eimicke JP, Moran A, Teresi J, Schwartz JE, et al. Value of ambulatory arterial stiffness index and 24-h pulse pressure to predict progression of albuminuria in elderly people with diabetes mellitus. Am J Hypertens 2007; 20 (5): 493-500.

10. Ankle Brachial Index Collaboration. Ankle brachial index combined with Framingham Risk Score to predict cardiovascular events and mortality: a meta-analysis. JAMA 2008; 300 (2): 197-208.

11. Kikuya M, Staessen JA, Ohkubo T, Thijs L, Metoki H, Asayama K, et al. Ambulatory arterial stiffness index and 24-hour ambulatory pulse pressure as predictors of mortality in Ohasama, Japan. Stroke 2007; 38: 11616.

12. Dolan E, Thijs L, Li Y, Atkins N, McCormack P, McClory S, et al. Ambulatory arterial stiffness as a predictor of cardiovascular mortality in the Dublin outcome Study. Hypertension 2006; 47 (4): 365-70.

13. Hansen TW, Staessen JA, Torp-Pedersen C, Rasmussen S, Li Y, Dolan E, et al. Ambulatory arterial stiffnes index predicts stroke in a general population. J Hypertens 2006; 24 (11): 2247-53. 